\title{
Asthma prevalence and deprivation: a small area analysis
}

\author{
Clare Salmond, Peter Crampton, Simon Hales, Simon Lewis, Neil Pearce
}

\begin{abstract}
Study objective-To investigate the relation between the prevalence of asthma symptoms in adults and deprivation in the area of residence.

Design-Two complementary surveys carried out between 1991-1993 yielding adult asthma symptom prevalence throughout New Zealand. Deprivation is measured by the NZDep91 index of deprivation for small areas.

Setting-New Zealand.

Participants-A random sample of 25042 adults aged $20-50$ years.

Main results-After controlling for possible confounding by age, gender, and ethnicity, the 12 month period prevalence rates of asthma in this representative sample of New Zealand adults are significantly higher in the three most deprived area categories than in the least deprived (tenth) category. The prevalence ratio for the most deprived category compared with the least deprived category is 1.29 with $95 \%$ confidence intervals (CI) 1.14 , 1.47. There is a linear increase in asthma prevalence with increasing area deprivation $\left(\chi_{1}^{2}=32.20, p<0.001\right)$. Independently, the rates are also $1.41(95 \%$ CI $1.29,1.54)$ times higher among Maori and 1.29 $(95 \%$ CI $1.10,1.52)$ times higher among the Pacific Island group than among the remaining, mostly European, respondents.
\end{abstract}

Conclusions-The relation between asthma in adults and area deprivation is unlikely to be attributable to study biases or confounding. Further work should examine the possible role of modifiable deprivation factors in this relation.

Health, Wellington

School of Medicine, Wellington, New

Zealand

C Salmond

P Crampton

$S$ Hales

Wellington Asthma

Research Group,

Wellington School of

Medicine, Wellington,

New Zealand

$\mathrm{S}$ Lewis

N Pearce

Correspondence to:

Clare Salmond, Department of Public Health, Wellington School of Medicine, PO Box 7343, Wellington South, New Zealand.

Accepted for publication 29 January 1999

Asthma is an increasingly common problem in New Zealand ${ }^{12}$ and worldwide. ${ }^{3}$ Although many causes of asthma are known or suspected further work is needed to identify potentially modifiable environmental factors. ${ }^{4-8}$ Socioeconomic status may be one such broad factor. This paper focuses on the specific socioeconomic concept of deprivation.

There is abundant evidence in the international literature of a strong relation between health status and deprivation. This relation has been demonstrated for a large number of health states and health status measures. ${ }^{9-13}$ In particular there is some recent evidence of relations between asthma prevalence, treatment and severity, and deprivation. ${ }^{14-24}$ In considering this evidence, however, it is important to distinguish between studies in children that mainly reflect cumulative asthma incidence, and studies in adults that may be influenced by differences in the prolongation and exacerbation of symptoms that may affect the duration of the condition. ${ }^{25}$

It is mainly in studies done in the 1960s and 1970s (for example, Mitchell and Dawson ${ }^{14}$ ) that asthma has been found to be more common in children in the higher social classes, but there has been less evidence of social class differences as the diagnosis of asthma has become more widespread. ${ }^{15} \mathrm{~A}$ recent review of 24 studies in children published since the 1960 s concluded that negative associations were about as numerous as positive associations, and most studies showed no association at all. ${ }^{16}$ The authors posited that the lack of clarity may be attributable to differing definitions of asthma, differing methods for assessing asthma, and different age groups studied. However, severe asthma seems to be more common in children in the lower social classes ${ }^{16}$ and hospital admissions because of asthma are higher in low socioeconomic status groups. ${ }^{16-24}$ For example, a study of schoolchildren in Aberdeen published in 1969 showed that the association between childhood asthma and socioeconomic status is strongly modified by degree of asthma severity. ${ }^{22}$

There have been fewer asthma prevalence surveys in adults, but most studies show evidence of greater symptom prevalence or reduced lung function in lower socioeconomic status groups. ${ }^{18-2026}$ Some of these findings could be attributable to social class differences in diagnostic labelling of wheezing in adults, ${ }^{27}$ but it is more likely that they reflect real differences in asthma prevalence that are because of prolongation and exacerbation of symptoms into adulthood. ${ }^{25}$

A national survey of asthma prevalence during 1991-3 provides an opportunity to gain substantive evidence concerning the relation between asthma prevalence and a new areabased measure of deprivation in adults.

\section{Methods}

The 1991-1993 asthma survey has been described in detail previously. ${ }^{2}$ A one page questionnaire was mailed to a national random sample of 35888 adults aged 20-44 years (at enrolment) selected from electoral rolls. The overall response (excluding ineligibles) was $82 \%$. We used the same operational definition of asthma as used in the European Community Respiratory Health Survey. ${ }^{3}$ A person was 
Table 1 New Zealand asthma survey response by area deprivation score

\begin{tabular}{llll}
\hline Deprivation score* & Respondents & $\begin{array}{l}\text { Asthma study } \\
\text { sampleł (\%) }\end{array}$ & $\begin{array}{l}\text { New Zealand } \\
\text { population (\%) }\end{array}$ \\
\hline 1 (least deprived areas) & 11.32 & 10.39 & 10.65 \\
2 & 10.85 & 10.26 & 10.26 \\
3 & 10.30 & 9.76 & 9.97 \\
4 & 9.96 & 9.44 & 9.97 \\
5 & 9.94 & 9.56 & 9.68 \\
6 & 9.48 & 9.36 & 9.71 \\
7 & 9.59 & 9.90 & 9.77 \\
8 & 9.45 & 9.88 & 9.76 \\
9 & 9.74 & 10.47 & 10.06 \\
10 (most deprived areas) & 9.36 & 10.97 & 10.17 \\
Number & 25042 & 34869 & \\
\hline
\end{tabular}

${ }^{\star}$ NZDep 91 value. †Excludes 624 respondents who could not be geocoded. $\ddagger$ Excludes 1019 persons who could not be geocoded

considered to have had asthma in the previous year if they had a positive response to one or more of the following three questions: (1) Have you been woken by an attack of shortness of breath at any time in the last 12 months? (2) Have you had an attack of asthma in the last 12 months? (3) Are you currently taking any medicine (including inhalers, aerosols or tablets) for asthma?

Age at the time of the survey was calculated from the date of birth given on the asthma questionnaire. Ethnicity was obtained as Maori, Pacific Islander, European, and/or Other, and then classified hierarchically into Maori or part (10.2\%), Pacific Islander or part $(2.5 \%)$, and a third group with European and/or Other ancestry $(79.6 \%+7.6 \%)$.

Deprivation in an area was measured by the NZDep 91 index of deprivation for small areas. ${ }^{13} 28$ The index was created from 1991 census data and is available for all meshblocks (the smallest administrative area used in the New Zealand Census of Population and Dwellings). The full index is a weighted combination of 10 proportions in a small area, typically consisting of one or two geographically contiguous meshblocks having in total at least 100 persons usually resident in them. The proportions are standardised for age (in four groups) and gender, and two are adjusted for household size and composition. The overall distribution of this index was then split into deciles to produce a 10 point scale of deprivation where 1 is least deprived, and 10 is most deprived. The deprivation value for a small area was assigned to each of its constituent meshblocks. These deprivation scores may be considered as an interval scale of measurement. Validation studies showed that depriva-

Table 2 One year period prevalence of asthma among New Zealand adults aged 20-50 years, by area deprivation score

\begin{tabular}{llll}
\hline Deprivation score & Respondents & $\begin{array}{l}\text { Prevalence of asthma } \\
(\%)\end{array}$ & Prevalence ratio \\
\hline 1 (least deprived areas) & 2836 & 13.1 & 1.0 \\
2 & 2717 & 12.8 & 0.98 \\
3 & 2580 & 13.1 & 1.00 \\
4 & 2493 & 15.0 & 1.14 \\
5 & 2490 & 14.9 & 1.14 \\
6 & 2374 & 14.7 & 1.13 \\
7 & 2402 & 14.9 & 1.25 \\
8 & 2366 & 16.4 & 1.43 \\
9 & 2440 & 18.6 & 1.49 \\
10 (most deprived areas) & 2344 & 19.5 & \\
address not geocodable & 624 & 16.8 & \\
Total & 25666 & & \\
ॠNZDep91 value & &
\end{tabular}

${ }^{\star}$ NZDep 91 value.
KEY POINTS

- Asthma prevalence is significantly associated with deprivation at an area level.

- The association, though not strong, is not explained by associations with the possible confounders of age, gender, or ethnicity.

- This study lends further weight to the case for reducing material deprivation on public health grounds.

tion measured by this index was strongly related to mortality, hospital admissions, and lung cancer registrations. ${ }^{1328}$

Analyses were performed using SAS. ${ }^{29}$ Generalised log linear models with a binomial error structure were used to describe the relation between asthma prevalence and area deprivation. The least deprived areas are the referent group in categorical analyses and the 10 point score was used to explore a linear relation. The largest, mostly European, group was the referent group for ethnicity.

\section{Results}

NZDep91 values were assigned to the 25042 respondents $(97.6 \%)$ with a meshblock geocodable address. The deprivation profile of the asthma study sample and the respondents is shown in table 1 along with the full distribution in New Zealand. There are slightly more persons living in deprived areas in the asthma sample than in the New Zealand population. Among those who responded, there are slightly fewer persons living in the most deprived areas, and conversely, slightly more in the least deprived areas, than in the whole of the country.

Overall $3912(15.2 \%)$ respondents are considered to have had asthma in the previous 12 months. The proportion with asthma varied significantly across the 10 deciles of area deprivation, from $12.8 \%$ to $19.5 \%$ (table 2 ). A generalised linear model showed that there was a significant linear trend in these proportions $\left(\chi_{1}^{2}\right.$ $=77.7, \mathrm{p}<0.001)$.

The effect of non-response on this trend depends on the relation between deprivation and/or asthma and the likelihood of response. If all people with asthma responded, regardless of their area deprivation, the linear trend in proportions is still significant $\left(\chi_{1}^{2}=16.6, p<\right.$ 0.001). If response among people with asthma was inversely proportional to deprivation, a more pronounced trend would result. A diminished trend would result only from proportionately fewer asthmatics in the most deprived areas not responding, which seems unlikely.

The proportion with asthma is significantly higher among Maori (22.0\%) and Pacific Islanders $(20.5 \%)$ than among the remaining, mostly European, group (14.3\%). The respective crude prevalence ratios and $95 \%$ confidence intervals are $1.54(1.42,1.67)$ and 1.43 $(1.23,1.67)$.

Controlling for age and gender, asthma prevalence varied with area deprivation score, being significantly greater in the three most 
Table 3 Generalised linear models * for asthma prevalence among New Zealand adults

\begin{tabular}{|c|c|c|c|c|c|c|c|c|}
\hline \multirow[b]{2}{*}{ Explanatory variables } & \multicolumn{2}{|c|}{ Model 1} & \multicolumn{2}{|c|}{ Model 2} & \multicolumn{2}{|c|}{ Model 3} & \multicolumn{2}{|c|}{ Model 4} \\
\hline & $P R \neq$ & $95 \% C I$ & $P R$ & $95 \% C I$ & $P R$ & $95 \% C I$ & $P R$ & $95 \% C I$ \\
\hline \multicolumn{9}{|l|}{ Area deprivation $\dagger$} \\
\hline 1 (least deprived) & 1.0 & & & & 1.0 & & 1.0 & \\
\hline 2 & 0.98 & $0.85,1.12$ & & & 0.97 & $0.85,1.12$ & 1.04 & $0.86,1.24$ \\
\hline 3 & 1.00 & $0.87,1.15$ & & & 1.00 & $0.87,1.15$ & 1.10 & $0.92,1.32$ \\
\hline 4 & 1.15 & $1.00,1.31$ & & & 1.14 & $1.00,1.30$ & 1.29 & $1.08,1.53$ \\
\hline 5 & 1.13 & $0.99,1.29$ & & & 1.12 & $0.98,1.28$ & 1.29 & $1.08,1.53$ \\
\hline 6 & 1.11 & $0.97,1.27$ & & & 1.09 & $0.95,1.25$ & 1.21 & $1.02,1.45$ \\
\hline 7 & 1.13 & $0.99,1.29$ & & & 1.08 & $0.95,1.24$ & 1.28 & $1.07,1.52$ \\
\hline 8 & 1.23 & $1.08,1.41$ & & & 1.19 & $1.04,1.35$ & 1.39 & $1.17,1.65$ \\
\hline 9 & 1.41 & $1.24,1.59$ & & & 1.30 & $1.14,1.48$ & 1.53 & $1.30,1.81$ \\
\hline 10 (most deprived) & 1.47 & $1.29,1.66$ & & & 1.29 & $1.14,1.47$ & 1.64 & $1.39,1.93$ \\
\hline \multicolumn{9}{|l|}{ Ethnicity } \\
\hline European and other & & & 1.0 & & 1.0 & & 1.0 & \\
\hline Maori & & & 1.52 & $1.40,1.64$ & 1.41 & $1.29,1.54$ & 1.66 & $1.49,1.84$ \\
\hline Pacific Islander & & & 1.41 & $1.21,1.64$ & 1.29 & $1.10,1.52$ & 1.41 & $1.17,1.71$ \\
\hline
\end{tabular}

*Models 1-3 used the ECRHS definition of asthma, a positive answer to at least one of three questions-woken by shortness of breath, having "asthma" or having medication for asthma; model 4 used only a positive answer to the shortness of breath question; all models also included age and gender. $\nmid N Z D e p 91$ value. $¥ P R$ : prevalence ratio. Values are exponentiated parameter estimates.

deprived deciles than in the least deprived decile (table 3, model 1). Adults living in the most deprived decile were almost one and a half times as likely as those in the least deprived decile to have suffered from asthma in the previous 12 months. As expected, ${ }^{2}$ Maori and Pacific Islanders had a significantly increased prevalence of asthma (model 2).

As there is a well known general association between ethnicity and socioeconomic status ${ }^{30-32}$ an association between ethnicity and deprivation would be expected. Thus the observed association between asthma and deprivation could simply reflect the ethnic composition in deprived areas. However, when ethnicity is included in the model the association between asthma and area deprivation is still significant but weaker (model 3). The three most deprived deciles have a significantly increased asthma prevalence over the least deprived decile, and the proportional increase is reduced to 1.3 times in the two most deprived deciles. The approximate linear trend is still apparent $\left(\chi_{1}^{2}=\right.$ $32.20, \mathrm{p}<0.001)$. In this model women have 1.27 times the prevalence of asthma among men $(95 \%$ CI $1.19,1.35)$ and age is significantly and negatively associated with asthma prevalence $\left(\chi_{1}^{2}=15.47, \mathrm{p}<0.001\right)$. There was no demonstrable differential effect of deprivation within ethnic groups, although this might be accounted for by the relatively small numbers of Maori and Pacific Islanders within each deprivation category.

Models including interactions between age group and both deprivation and ethnicity showed, as found previously, ${ }^{1}$ that there was a significant interaction with ethnicity $(p=$ $0.050)$, but not with deprivation as well ( $\mathrm{p}=$ $0.19)$. However, when the interaction term with ethnicity was included in the model, the prevalence ratios for deprivation categories remained unchanged (to two decimal places).

Models were also developed for each of the three individual questions used in the European Community Respiratory Health Survey definition of asthma. The model for the first question (being woken by shortness of breath, table 3 model 4) showed a stronger relation to area deprivation than the model for the ECRHS definition, which required a positive answer to any of the three questions, while the models for the other two questions (asthma attacks and asthma medication use) showed weaker and non-significant relation (not shown).

\section{Discussion}

The 12 month age/gender adjusted period prevalence rates of asthma in this representative New Zealand sample of adults aged 20-50 years are 1.19-1.30 times higher in the most deprived areas than in the least deprived areas. Independently, the rates are also 1.41 times higher among Maori and 1.29 times higher among Pacific Islanders but we focus on the findings for area deprivation because the ethnic differences have been discussed elsewhere. ${ }^{12}$

Following convention, asthma in this study is defined as a positive response to at least one of three questions. However, using just the shortness of breath question to define asthma there is a stronger relation than observed for the conventional definition, with prevalence rates becoming steadily higher among the more deprived areas, reaching 1.64 time higher in the most deprived areas compared with the least. Combined with the absence of any linear relation between deprivation and either of the other two individual questions, which presuppose access to medical care (having "asthma", or having medication for asthma), this suggests that a relation between access to medical care (which may be reduced in deprived areas) and some aspect of socioeconomic status may have led to an underestimate of the effect of deprivation when using the ECRHS definition of asthma. Nevertheless, these relations between asthma prevalence and area deprivation are not strong and it is therefore important to consider possible sources of bias as explanations for the observed increased prevalence rates.

As the sample of New Zealanders used in the asthma surveys is closely representative of the whole population it is unlikely that selection bias would have more than a minimal effect on the observed associations. Although a nonresponse bias is evident, the sensitivity analysis suggests that it cannot account completely for the observed relation between asthma and area 
deprivation. In a previous report the authors considered that non-response bias had little effect on reported symptom prevalence. ${ }^{1}$ Thus the estimate of the effect of area deprivation on asthma prevalence, controlling for ethnicity, is also unlikely to be substantially affected by non-response bias.

There may be some random misclassification of asthma by the screening questions in the questionnaire. In particular, there may be some adults with respiratory symptoms such as cough or wheezing that are likely to be associated with smoking rather than asthma itself. However, the questions we used have validated well against physician diagnosed asthma, and have in fact been found to have greater validity than supposedly more "objective" measures such as bronchial hyperresponsiveness testing. ${ }^{33}$ Furthermore, the composite definition of asthma that we used is based on "asthma attacks", use of asthma medications, or "waking with an attack of shortness of breath", and does not focus on symptoms such as cough or wheeze; thus, it seems unlikely that our findings are explained by smoking related misclassification of asthma. Similarly, the use of deprivation of an area at the time of the 1991 census may have caused some minor, random misclassification of area deprivation at the time each questionnaire was answered because of changes of residence, although generally between neighbourhoods with similar levels of deprivation. The effect of these random misclassifications would be to slightly underestimate any real association of asthma with area deprivation.

Possible confounding of the relation between asthma and area deprivation by the usual demographic factors-age, gender, and ethnicity - has been controlled in the analyses. Smoking (in adults) and exposure to environmental tobacco smoke (in children) are known to be associated with the development of asthma ${ }^{34} 35$ but as smoking is part of the causal chain that leads from deprivation to asthma ${ }^{36}$ it is inappropriate to control for it when assessing the overall effect of deprivation. Nevertheless, it would be interesting to see to what extent smoking explained the observed association. However, smoking information was not collected in our survey. Family size (not obtained in this study) is negatively associated with asthma prevalence ${ }^{37}$ and is therefore unlikely to explain the association between deprivation and asthma prevalence. If such confounding is present our figures are likely to underestimate of the size of the association. Other major confounders are unlikely.

Study biases, then, are unlikely explanations for the observed association. Thus, if the association is causal, deprivation must precede the onset of asthma symptoms. Although the present cross sectional survey cannot examine this issue, it is unlikely that the existence of a condition like asthma could lead to deprivation except in extreme cases (for example, if severe asthma affects educational or employment opportunities). The observed linear increase in asthma prevalence with increasing deprivation is support for a causal relation.
Various factors have been linked to asthma, including exposure to allergens, air pollution (especially tobacco smoke), diet, respiratory viral infections, fetal growth and family sizealthough findings have been quite inconsistent. . $^{523243538-40}$ It seems plausible that at least some of these factors could be on the causal pathway between material deprivation - acting at the level of communities and/or individuals - and asthma. For example, childhood patterns of respiratory infections may be influenced by extremes of overcrowding or social isolation ${ }^{41}$; it may be more difficult to maintain a healthy diet in a deprived area because of cost or lack of shops or transport; smoking in adults ${ }^{36}$ and chronic long term exposure to environmental tobacco smoke in children $^{21}$ are likely to be more common in deprived homes and communities.

As noted above, the ethnic differences have been discussed elsewhere,${ }^{12}$ but it is interesting to briefly consider possible explanations for the ethnic differences, as these may also be relevant to area deprivation. There is very little ethnic difference in asthma prevalence in children in New Zealand ${ }^{42}$ but prevalence differences emerge with increasing age. ${ }^{125}$ The reasons for this are unclear, but it seems likely to be attributable at least in part to a duration effect rather than an incidence effect-that is, the incidence of asthma is similar in Maori and non-Maori children but Maori children experience more exacerbations and prolongation of symptoms, and the prevalence does not therefore decline with age as it does in non-Maori. Although this is probably in part because of differences in the asthma risk factors mentioned above (particularly tobacco smoking), a major review concluded that these differences were also because of problems of access to adequate health care and asthma education for Maori with asthma. ${ }^{42}$ For example, Maori children who gain access to health care are less likely to be prescribed preventive medication. ${ }^{43}$ It is unclear whether the same process may be occurring for socioeconomic differences in asthma prevalence, and it is certainly possible that our findings are because of differences in disease duration rather than incidence. It would clearly be useful to examine area deprivation and asthma in children and adults in the same population, and to follow up populations over time to determine the causes of the asthma prevalence and severity differences in adults that we have observed.

Our findings lend further weight to the case for reducing material deprivation on public health grounds. In the primary prevention of asthma, social policies that tackle deprivation at the community level may prove effective, as well as attempting to modify personal risk factors.

Funding: this study was funded in part by the New Zealand Asthma Foundation, Lotteries Health and the Health Research Council of New Zealand. The Wellington Asthma Research Group is supported by a Programme Grant from the Health Research Council of New Zealand.

Conflicts of interest: none. 
1 Crane J, Lewis S, Slater T, et al. The self reported prevalence of alanders. $N Z$ of asthma symptoms am

2 Lewis S. Geographical variation in the prevalence of asthma symptoms in New Zealand. N Z Med f 1997;110:286-9.

3 ECRHS. Variations in the prevalence of respiratory symptoms, self reported asthma attacks, and use of asthma medication in the European Community Respiratory Health Survey (ECRHS). Eur Respir F 1996;9:687-95.

4 Burney P. Asthma epidemiology. Br Med Bull 1992;48:1022.

5 Seaton A, Godden D, Brown K. Increase in asthma: a more toxic environment or a more susceptible population? Thorax 1994;49:171-4.

6 Newman-Taylor A. Environmental determinants of asthma. Lancet 1995;345:296-9.

7 Strachan D. Time trends in asthma and allergy: ten questions, fewer answers. Clin Exp Allergy 1995;25:791-4

8 Von Mutius E. Towards prevention. Lancet 1997;350 (suppl

9 McLoone P, Boddy F. Deprivation and mortality in Scotland, 1981 and 1991. BMF 1994;309:1465-70.

10 Carstairs V, Morris R. Deprivation: explaining differences in mortality between Scotland and England and Wales. $B M \mathcal{F}$ 1989;299:886-9.

11 Black D, Morris JN, Smith C, et al. Inequalities in Health, The Black Report, The Health Divide. London: Penguin Books, 1992.

12 Morris R, Carstairs V. Which deprivation? A comparison of selected deprivation indices. F Public Health Med 1991;13 318-26.

13 Crampton P, Salmond C, Sutton F. NZDep91: a new index of deprivation. Social Policy Fournal of New Zealand 1997;9: 186-93.

14 Mitchell RG, Dawson B. Educational and social characterisitcs of children with asthma. Arch Dis Child 1973;48:46771 .

15 Littlejohns P, MacDonald LD. The relationship between severe asthma and social class. Respir Med 1993;87:139-43.

6 Mielck A, Reitmeir P, Wjst M. Severity of childhood asthma by socioeconomic status. Int f Epidemiol 1996;25:388-93.

17 Italian Studies on Respiratory Disorders in Childhood and the Environment (SIDRIA). Asthma and respiratory symptoms in 6-7 yr old Italian children: gender, latitude, urbanization and socioeconomic factors. Eur Respir $\mathcal{F} 1997$ 10:1780-6.

18 Watson J, Cowen P, Lewis R. The relationship between asthma admission rates, routes of admission, and socioeconomic deprivation. Eur Respir F 1996;9:2087-93.

19 Walters S, Phupinyokul J, Ayres J. Hospital admission rates for asthma and respiratory disease in the West Midlands: their relationship to air pollution levels. Thorax $1995 ; 50$ : 948-54.

20 Erzen D, Carriere C, Dik N, et al. Income level and asthma prevalence and care patterns. Am $\mathcal{F}$ Resp Crit Care Med 1997;155:1060-5

21 Burr M, Verrall C, Kaur B. Social deprivation and asthma. Respir Med 1997;91:603-8.

22 Dawson B, Horobin G, Illsley R, et al. A survey of childhood asthma in Aberdeen. Lancet 1969;i:827-30.
23 Weitzman M, Gortmaker S, Sobol A. Racial, social, and environmental risks for childhood asthma. Am $\mathcal{F}$ Dis Child environmental risks

24 Schwartz J, Gold D, Dockery D, et al. Predictors of asthma and persistent wheeze in a national sample of children in the United States. Am Rev Respir Dis 1990;142:555-62.

25 Pearce N, Beasley R, Burgess C, et al. Asthma epidemiology: principles and methods. New York: Oxford University Press, 1998:80.

26 Eachus J, Wiliams M, Chan P, et al. Deprivation and cause specific morbidity: evidence from the Somerset and Avon survey of health. BMf 1996;312:287-92.

27 Littlejohns P, Ebrahim S, Anderson HR. The prevalence and diagnosis of chronic respiratory symptoms in adults. and diagnosis of chronic

28 Salmond C, Crampton P, Sutton F. NZDep91: A New Zealand index of deprivation. Aust $N Z \mathcal{F}$ Public Health 1998;22:95-7.

29 SAS System [program]. 6.12 version. Cary, NC: SAS Institute, 1997.

30 Pearce N, Pomare E, Marshall S, et al. Mortality and social class in Maori and nonMaori New Zealand men: changes between 1975-7 and 1985-7. N Z Med F 1993;106:193-6.

31 Pomare E, Keefe-Ormsby V, Ormsby C, et al. Hauora Maori Standards of Health III. Wellington: Te Ropu Rangahau Hauora a Eru Pomare; Wellington School of Medicine, 1995.

32 Smith A, Pearce NE. Determinants of differences in mortality between New Zealand Maoris and non-Maoris aged 15-64. NZ Med f 1984;97:101-8.

33 Burney PGJ, Laitinen LA, Perdrizet S, et al. Validity and repeatability of the IUALTD (1984) bronchial symptoms questionnaire:an international comparison. Eur Respir $\mathcal{f}$ 1989;2:940-5.

34 Flodin U, Jonsson P, Ziegler J, et al. An epidemiologic study of bronchial asthma and smoking. Epidemiology 1995;6: 503-5.

35 National Health and Medical Research Council. The health effects of passive smoking. Canberra, Australia: National Health and Medical Research Council, 1997.

36 Kleinschmidt I, Hills M, Elliott P. Smoking behaviour can be predicted by neighbourhood deprivation measures. 7 Epidemiol Community Health 1995;49 (suppl 2):S72-7.

37 Crane J, Pearce N, Shaw R, et al. Asthma and having siblings. [Letter]. BMF 1994;309:272.

38 Martinez F. Role of viral infections in the inception of asthma and allergies during childhood: could they be protective? Thorax 1994;49:1189-91.

39 Balfe D, Crane J, Beasley R, et al. The worldwide increase in the prevalence of asthma in children and young adults. Continuing Medical Education 1996;14:433-42.

40 Shaheen S. Discovering the causes of atopy. BMF 1997;314: 987-8.

41 Reading R. Social disadvantage and infection in childhood. Sociology of Health and Illness 1997;19:395-414.

42 Pomare E, Tutengaeha H, Ramsden I I, et al. Asthma in Maori people. NZ Med f 1992;105:469-70.

43 Mitchell EA. Racial inequalities in childhood asthma. Soc Sci Med 1991;32:831-6. 